\title{
La escuela transformadora. Evidencias sobre las relaciones entre educación y género. Una propuesta teórica de interpretación
}

\author{
Adriana Marrero
}

\section{Resumen}

El artículo se propone discutir la tesis reproductivista de la escuela aplicada a las relaciones de género, mostrando la capacidad de los sistemas educativos para generar efectos contrarios a los que predice la teoría de la reproducción. Para ello, se atiende a los resultados de los sistemas educativos en el mundo y a los microprocesos de interacción en espacios universitarios, a través de la observación directa del comportamiento de hombres y mujeres y del análisis sistemático de discursos producidos en instancias de entrevista y de discusión grupal, para el caso uruguayo. Se concluye proponiendo una interpretación teórica sobre los distintos niveles de la construcción normativa de la realidad escolar.

Palabras clave: género, educación, teoría de la reproducción.

Abstract. Transformative school. Evidences on the relations between education and gender. A theoretical proposal of interpretation

The article sets out to discuss to the mainstream thesis of the school applied to the gender relations, showing the capacity of the educative systems to generate opposite effects to which it is predicted by the "reproduction theory». For it, are taken in account the results of the educative systems in the world and the micro process of interaction in university spaces, through the direct observation of the behavior of men and women and of the systematic analysis of speeches produced in occasion of interviews and group discussion, for the Uruguayan case. One concludes proposing a theoretical interpretation on the different levels of the normative construction of the school reality.

Key words: gender, education, reproduction theory.

\section{Sumario}

El problema La tasa de actividad

La relación entre educación y género

Las mujeres: discursos y prácticas

La revisión del reproductivismo: Los hombres... puntos de partida

Los resultados femeninos en números Una interpretación: el doble nivel del orden escolar

La especialización por carreras

Bibliografía 


\section{El problema}

La llamada teoría de la reproducción, que ha venido cediendo terreno en las últimas décadas, se encuentra, en los hechos, lejos de perder toda su vigencia. Esto puede deberse a dos razones: $a$ ) por un lado, es claro que el reproductivismo no es aplicable a muchos sistemas educativos que han logrado producir más «transformación» que «reproducción» en los resultados del alumnado proveniente de distintas clases sociales. Pero también es verdad que, en otros sistemas educativos, las tasas diferenciales de rezago, de abandono, de repetición, de especialización por tipos de educación, constituyen todavía hoy una evidencia innegable del insuficiente papel que cumple allí la escuela como amortiguadora o transformadora de las desigualdades económicas. En Uruguay, un país donde la enseñanza es gratuita en todos los niveles, los niños pertenecientes al $20 \%$ de hogares más pobres tienen sólo un $80 \%$ de probabilidades de culminar primaria, un $29 \%$ de finalizar la enseñanza media y un $20 \%$ de completar dieciséis años de educación, contra el $97 \%$, el $78 \%$ y el $66 \%$ de los hogares del 20\% más rico, respectivamente (ANEP, 2003). Además, este país, clasificado como de alto desarrollo humano por el PNUD, es el que presenta, en el contexto de Latinoamérica, una deserción ${ }^{1}$ que correlaciona más claramente con variables socioeconómicas: el 63\% del total de desertores se concentra en el $25 \%$ de los hogares más pobres, veinte puntos más que el promedio latinoamericano. Entonces, al menos en algunas sociedades, se puede decir todavía que la teoría de la reproducción goza de buena salud y lo seguirá haciendo hasta que la escuela logre distribuir de mejor manera las oportunidades educativas.

Por otro lado, la teoría de la reproducción parece mantenerse inmune a la falsación, aún en aquellos casos en los que la información contradice las predicciones de la teoría. Eso ocurre, principalmente, en la teoría de la reproducción aplicada al género, que parece inmune a la evidencia en contrario, con lo cual se transforma en una especie de «ideología» refractaria a la crítica.

El propósito de este artículo es exponer el reproductivismo de género, discutirlo a la luz de la información disponible y, a partir de una investigación propia, aportar nueva evidencia empírica para su contrastación. Finalmente, propondremos una lectura de la realidad escolar alternativa que permita explicar mejor tanto los fenómenos de discriminación de las mujeres tantas veces observados, como el notorio éxito escolar de las mujeres. Se concluye mostrando el carácter transformador de la escuela, por el cual las mujeres logran convertir su posición subordinada en las relaciones de género en posiciones ventajosas en la obtención de credenciales educativas.

1. En el trabajo que es fuente de estos datos, se considera como deserción a aquellos jóvenes que, no asistiendo a centros educativos en el momento de la encuesta, declaren haber dejado de estudiar definitivamente o que aún no lo han decidido (ANEP, 2003). 


\section{La relación entre educación y género}

En un sentido muy amplio, puede decirse que la relación entre educación y género ha sido abordada, mayoritariamente, través de un reproductivismo que podríamos denominar lábil. Contrariamente a lo que postula la teoría de la reproducción aplicada a la clase social, que se apoyaba fuertemente en la estadística para mostrar un eventual efecto reproductivo de la escuela en la transmisión intergeneracional del capital económico, en materia de género la teoría parece moverse con rapidez hacia otros campos, inmediatamente después de dejar constancia de la principal evidencia en su contra: el éxito «numérico» de las mujeres en la escuela.

Los dos argumentos hacia los cuales «fugan» los teóricos de la reproducción son, por un lado, la constatación de que la feminización no se traduce inmediatamente en ventajas económicas y profesionales en el mundo posteducativo, debido a que mantiene y consagra la división del trabajo a través de la especialización disciplinaria; por otro, el enfoque de los microprocesos sociales y del currículo oculto en el interior de la escuela, para mostrar los modos ocultos de transmisión y de reproducción de estereotipos de género en las aulas.

Dentro de los primeros, se destaca, por cierto, Pierre Bourdieu, quien, en un texto de 1964, afirmaba: «[...] las mujeres son a los varones como los estudiantes de clase baja a los estudiantes provenientes de medios privilegiados. Las posibilidades objetivamente más débiles de tener una profesión y sobre todo una profesión intelectual (siempre tomadas en consideración en la conducta, aun cuando sean rechazados por la ideología) impiden a las mujeres lanzarse al juego intelectual con todo el ardor al que sólo autoriza el olvido sin riesgos de un porvenir garantizado» (Bourdieu y Passeron, 2003: 94). Treinta años más tarde, el aumento del acceso de las mujeres a la enseñanza media y superior, y sus mayores "posibilidades objetivas» de lograr una profesión intelectual, no le llevan, sin embargo, a renegar del papel reproductivo de la escuela en este aspecto. Para él, la feminización matricular representa "sin duda", «uno de los caminos más importantes en la condición de las mujeres y uno de los factores más decisivos de la transformación de esa condición» (Bourdieu, 1999: 112). Pero, una vez más, este auspicioso resultado en la escuela se contrasta con la escasa suerte de las mujeres en el mercado profesional. Por un lado, se ha dado un fuerte «incremento de la representación de las mujeres en las profesiones intelectuales o la administración y en las diferentes formas de venta de servicios simbólicos»; por otro, se ha producido «una intensificación de su participación en las profesiones próximas a la definición tradicional de las actividades femeninas (enseñanza, asistencia social, actividades relacionadas con la medicina)» (Bourdieu, 1999: 113). Por lo tanto, según Bourdieu, todo cambia para que todo siga como está: «las posiciones que se feminizan, o bien ya están desvalorizadas [...] o bien son declinantes, con lo que su devaluación se ve redoblada, en un efecto de bola de nieve, por la deserción de los hombres que ha contribuido a suscitar» (Bourdieu, 1999: 114). Charles Soulié (Cf. Bourdieu, 1999: 114) sostiene, en el mismo sentido, que la igualación de las 
posibilidades de acceso no deberían ocultar las desigualdades en la apropiación de diferentes currículos y carreras: «[...] las chicas están mucho menos representadas en las secciones más cotizadas, su representación sigue siendo muy inferior en las secciones científicas, mientras que se incrementa en las secciones literarias». Este fenómeno es extensible a todas las disciplinas, en cada una de las cuales se asigna «a los hombres lo más noble, lo más sintético, lo más teórico, y a las mujeres, lo más analítico, lo más práctico, lo menos prestigioso». También Ulrich Beck (1998) considera a la feminización universitaria como una «igualación revolucionaria de las oportunidades educativas». Sin embargo, enfoca de inmediato otros dos factores que parecen desmentir aquella aparente igualación: a) La especialización disciplinaria, según la cual las mujeres siguen estando sobrerrepresentadas en algunas carreras, tales como Pedagogía, Lingüística o Ciencias del Espíritu (Beck, 1998: 134-135), y b) el mantenimiento de la asimetría en el sistema ocupacional, ya que la feminización educativa vendría a confirmar "la vigencia de la jerarquía sexual-estamental inversa: cuanto más «central» es un ámbito para la sociedad, cuanto más "poderoso» es un grupo, tanto menos representadas están las mujeres» (Beck, 1998: 135). En conclusión, para Beck, la vigencia de estas inquebrantables «leyes estamentales de género» (Beck y Beck, 2001: 37) hacen que, en el ámbito económico, las mujeres sólo logren conquistar «barcos que se hunden» (Beck, 1998: 136) o, al menos, en peligro de hacerlo (Beck y Beck, 2001: 39). Finalmente, desde una perspectiva posmoderna, Gilles Lipovetsky (1999) niega que los estereotipos de sexo sean una pesada herencia del pasado tendientes a desaparecer. Aunque considera a la expansión de la educación universitaria entre las mujeres como «uno de los factores estructurales que contribuyeron a precipitar el declive del estereotipo de la esposa-ama de casa» (Lipovetsky, 1999: 209), no cree que éste haya sido además un factor determinante en la predisposición de aquéllas para integrarse en el mercado de trabajo. Constata, además, la permanencia de la dispar distribución profesional de mujeres y hombres: «Salta a la vista: a despecho de la terciarización de la economía y de la progresión escolar de las jóvenes, desde hace veinte o treinta años hombres y mujeres se reparten sin modificaciones sustanciales entres los diferentes sectores del mundo laboral» (Lipovetsky, 1999: 225). Citando a Baudelot y Establet, subraya que los varones se concentran en las especialidades "prometeicas» orientadas al dominio del mundo y de las personas, mientras que las mujeres están sobrerrepresentadas en la educación y la salud. Para él, entonces, "tras el avance de la cultura igualitaria, se recompone la asimetría de las expectativas y de los roles sexuales, la disyunción tradicional hombre público/mujer privada» (Lipovetsky, 1999: 271).

Estas teorías hacen poco por explicar cuál sería el papel de la institución educativa en la desigual distribución de las recompensas, bien en el mercado de trabajo, bien en el mercado de «reconocimiento» social asociado a las distintas ocupaciones. El que ciertas ocupaciones se encuentren o no desvalorizadas, y que sea más difícil que las personas que las desempeñan tengan retornos económicos, políticos o sociales acordes con su nivel de calificación, no es una 
responsabilidad que pueda ser atribuida, sin más, a la escuela, sino, más plausiblemente, a los ámbitos exteriores a ella, que es donde se transan las credenciales asociadas a esas ocupaciones. Hablar de la discriminación femenina en el mercado de trabajo cuando se examina el éxito femenino en el campo educativo, contribuye poco a la clarificación del fenómeno y a la identificación de sus causas.

En la segunda categoría, es posible encontrar un conjunto heterogéneo de investigaciones sociológicas y etnográficas, originadas en el mundo anglosajón, pero con relevantes exponentes en otras partes del globo. Estos enfoques han coincidido en señalar las múltiples formas de discriminación de las alumnas en el espacio escolar, que van desde lo curricular, donde se denuncia el predominio de una cultura androcéntrica, hasta las pautas de interacción en el aula o en el patio, que favorecen a los alumnos varones. Mary O’Brien, por ejemplo - para quien «la meta de la educación feminista no es la igualdad en el conocimiento, el poder y la riqueza, sino la abolición del género como realidad cultural opresiva»— subraya que la escuela no sólo reproduce la división del trabajo, sino, en términos más generales, «el dominio de los hombres sobre las mujeres» (O’Brien, 1983). Dale Spender (cfr. Acker, 1995) pone el acento en el sesgo masculino del conocimiento «humano" como consecuencia de un largo proceso de desvalorización y silenciamiento de las contribuciones femeninas al saber, al mismo tiempo que enfoca las diferencias en las pautas de comportamiento cotidianas en las escuelas, para mostrar cómo el profesorado dedica mayor atención y tiempo a los varones. Mahony hace la misma observación: las chicas obtienen menos atención que los varones, quienes, además, con frecuencia, ridiculizan sus intervenciones (Acker, 1995).

Fuera del mundo anglosajón, se ha llegado a resultados similares. Marina Subirats y Cristina Brullet (Subirats y Brullet, 1988; Subirats, 1999), por ejemplo, se vale de la categoría de "currículo oculto" para determinar "cuál es el sistema de valores transmitido y si se hacen diferencias no sólo respecto a los individuos, sino también respecto a la valoración de unas pautas de género que forman parte del sistema cultural» (Subirats y Brullet, 1988: 24). También desde el currículo oculto, Graciela Morgade (2001) se centró en las representaciones que mujeres y varones construyen en relación con su propio rendimiento, concluyendo que «la bipolaridad escolar de género que encontramos en la relación con el conocimiento escolar y que sin duda marca las subjetividades de chicos y chicas, se fundamenta por naturalización: los varones, por naturaleza, "son más inteligentes“" (Morgade, 2001: 72).

Tal como están formuladas, estas últimas teorías tampoco dan una respuesta satisfactoria a las causas del éxito educativo femenino, especialmente a nivel universitario. Por el contrario, el fenómeno despierta aún mayor interés: si la escuela trata tan mal a las niñas y a las jóvenes mujeres - las discrimina, las oprime, las ridiculiza, las violenta, las ignora, las invisibiliza-, es difícil comprender que quieran permanecer en la escuela, que progresen en ella más y mejor que sus compañeros hombres, que superen a sus compañeros en el momento de egresar de carreras universitarias y que hagan lo posible por regre- 
sar a la escuela luego, como docentes, como maestras o profesoras de todos los niveles. Tampoco se comprende esta permanencia en la escuela, si el indiscutible sesgo masculino del currículo tuviera los efectos que se le atribuyen: el convencer a las mujeres que no son ellas las que están destinadas a obtener logros en el terreno profesional y público.

\section{La revisión del reproductivismo: puntos de partida}

El reproductivismo de género merece un nuevo examen; el éxito femenino en la educación todavía está pendiente de explicación. Esta es la cuestión que me propongo abordar ahora. Para ello, parto de tres supuestos básicos, que son:

a) La evaluación del papel de la escuela en la reproducción de desigualdades debería circunscribirse al espacio escolar y a sus resultados. Esto supone distinguir los bienes y los mecanismos de distribución que son propios del sistema educativo - los conocimientos y los reconocimientos, las calificaciones, las credenciales, etcétera- de lo que es ajeno a él, en particular, de los mecanismos de distribución propios del mercado. A diferencia de lo que parecen sugerir las teorías expuestas en primer lugar, las condiciones de obtención de las credenciales educativas son distintas de las condiciones dentro de las cuales esas credenciales serán transadas luego, y ambas tienen lugar en ámbitos separados: la escuela y el mercado (económico y simbólico). Esto supone, entonces, dejar entre paréntesis la desigualdad en el mercado entre varones y mujeres, pues éste no es un fenómeno escolar ni tiene naturaleza educativa.

b) En cuestiones de género, la teoría de la reproducción debería ser evaluada con los mismos criterios que los aplicados en el examen de las relaciones de clase, esto es, analizando las tasas diferenciales de éxito y de fracaso, y toda otra variable que permita poner en cuestión la hipótesis del papel reproductor de la escuela de la subordinación femenina. Si la escuela reprodujera las asimetrías que caracterizan a las relaciones de género, cabría esperar, al igual que lo observado en la reproducción de las clases sociales, un mayor fracaso — repetición, rezago y abandono- de la categoría subordinada, esto es, de las mujeres. Si esto no es así, no deberíamos dudar en descartar la teoría.

c) La exigencia de circunscribir el estudio de los efectos de lo escolar a lo propiamente escolar, supone aceptar que no todas las influencias a las que están sometidos las estudiantes y los estudiantes durante su vida escolar provienen de la vida en la escuela. La jornada escolar es claramente minoritaria a lo largo de la infancia y la juventud, y durante el resto del tiempo, la familia, el grupo de pares y los medios de comunicación de masas, entre otros, ejercen una influencia que no es posible menospreciar, aunque sea difícil de medir. A efectos de examinar la teoría de la reproducción, no basta entonces con detectar la vigencia de estereotipos de género dentro del ámbito escolar, sino que hay que mostrar que la presencia de esos estereotipos es 
mayor, o más poderoso, que la que está vigente en esos otros ámbitos: la familia, el grupo de pares y los medios de comunicación. Estas comparaciones parecen estar todavía pendientes de realización.

Si aceptamos estos supuestos, podemos decir, explicitándolo mejor, que si la escuela "reprodujera» las relaciones de género, debería reproducir el isomorfismo entre la subordinación social y económica de la categoría desfavorecida - las mujeres - y la subordinación en las recompensas educativas otorgadas por la escuela — promoción y credenciales_, lo que se expresaría en: a) mayores tasas de fracaso femenino (por efecto de la experiencia de subordinación); $b$ ) alta especialización por carreras que expresan una extensión de los tipos de trabajo tradicionales, y $c$ ) expresión escolar del modelo tradicional de «inactividad» femenina frente a «actividad» masculina (por efecto de la división entre lo "privado» feminizado y lo "público» masculinizado), visible a través de la tasa de actividad de los estudiantes universitarios, mujeres y varones. Por otro lado, d) debería ser observable una reproducción de la discriminación a través de microprocesos de interacción en las aulas, de un modo perceptible aún para los partícipes en la interacción. Se podría alegar que hay algunos fenómenos sociales cuya existencia es independiente de las conciencias de los sujetos. Pero, en este caso, el fenómeno debe ser susceptible de observación a través de otros medios, por ejemplo, mediante los resultados diferenciales de promoción y egreso. En todo caso, si la subordinación y la degradación existieran, lo que hay que mostrar — sin invalidar por ello los hallazgos empíricos de algunas de estas investigaciones - es que son más frecuentes o más notorias que las que rigen en el mundo extraescolar o, al menos, más perceptibles por los propios partícipes en la interacción.

Para poner a prueba estas proposiciones, me valdré de los resultados obtenidos en la investigación El asalto femenino a la universidad. Los senderos meritocráticos para una sobrecalificación compensatoria, llevada a cabo entre los años 2005 y 2006 en la Universidad de la República O. del Uruguay (UR), además de otros datos disponibles, generados por organismos internacionales. La investigación comprendió los siguientes instrumentos: $a$ ) análisis de datos censales de la población estudiantil de la UR; $b$ ) entrevistas en profundidad a docentes universitarios, mujeres y hombres de distintas facultades y distinto grado académico; $c$ ) entrevistas en profundidad a estudiantes universitarios hombres y mujeres de distintas facultades; d) grupos de discusión de estudiantes mujeres y hombres de distintas facultades; $e$ ) observación participante en una asamblea estudiantil multitudinaria, como modo de acceder a un espacio público de debate y decisión en una universidad cogobernada, a instancias de una fuerte disputa por la elección de un decano.

\section{Los resultados femeninos en números}

Todos los datos sobre desempeño escolar coinciden en señalar el éxito de las mujeres a todos los niveles y, en particular, el universitario. Más aún: cuanto 
mejor es el sistema educativo, mejor parecen desempeñarse las mujeres en él. Los datos del PNUD para el año 2005 muestran que, en los países de alto desarrollo humano, la tasa de matriculación neta femenina es superior a la de los hombres, lo que aumenta a medida que aumenta el nivel educativo. En el nivel de enseñanza universitaria, en 42 de los 57 países incluidos, la tasa de matriculación neta femenina es superior a la masculina, en uno de ellos es igual, y sólo en los 14 restantes es inferior ${ }^{2}$. Aunque esta relación se verifica sólo entre los países con alto desarrollo humano, el dato permite discutir la hipótesis del papel reproductivo que jugarían los sistemas educativos modernos en la perpetuación de las desigualdades de género, y ratifica la impresión de que los buenos sistemas educativos benefician a las mujeres. Si esto es así, la escuela actuaría mejorando y no disminuyendo las probabilidades de las mujeres para mejorar su condición social a través de la educación. A lo largo de todos los niveles educativos, las mujeres repiten menos, se rezagan menos y abandonan con menos frecuencia sus estudios.

En Uruguay, el 73\% del estudiantado de nivel terciario —universidades, institutos universitarios y centros de formación de docentes- son mujeres. Los varones representan el $61 \%$ de los repetidores en enseñanza primaria; en enseñanza secundaria, la distancia entre la matrícula de mujeres y varones se va ampliando a medida que progresamos desde los primeros años hasta el bachillerato: mientras en el primer año, las mujeres representan algo más del 51\% de los inscriptos, seis años después, en el último curso de bachillerato, alcanzan casi el 58\% (MEC, 2005). Dentro de la universidad, las mujeres también tienen rendimientos consistentemente superiores: al ingreso, son el $64,7 \%$ de la matrícula, pero representan el $67,4 \%$ del egreso total. Y esto en un sistema educativo que, como vimos, ejerce un fuerte efecto de selección socioeconómica de sus estudiantes.

\section{La especialización por carreras}

Tal como hemos visto, éste es un argumento utilizado con frecuencia, y al parecer no carece de sustento: las mujeres son minoría en algunas especialidades y dominan ampliamente en otras. Pero parece que estas diferencias tienden a disminuir o a desaparecer. En Uruguay, de 14 facultades de la UR, sólo tres tienen una matrícula inicial minoritariamente femenina: Agronomía $(21,7 \%)$, Ingeniería (29\%) y Arquitectura (47\%). Pero cuatro años después, tomando en cuenta el egreso, las mujeres ya son mayoría en Arquitectura (53\%), y mejoran notoriamente su proporción en Agronomía (27,5\%). Sólo en Ingeniería es posible observar un fuerte sesgo negativo de las mujeres al egreso, que cae casi a la mitad de los que ingresan: $15,2 \%$. Esto no quiere decir, sin embargo, que las ciencias exactas y naturales sean un terreno exclusivamente masculino. En

2. <http://hdr.undp.org/reports/global/2005/espanol/pdf/HDR05_sp_complete.pdf> (p. 331), consultada el 9 de diciembre de 2005. 
otras disciplinas científicas, las mujeres obtienen resultados notables: en Ciencias Básicas, el $62,5 \%$ de los estudiantes que ingresan son mujeres; pero, cuatro años más tarde, las mujeres son, entre los egresados, el 66,2\%. En la Facultad de Química ingresa un 72,7\% y egresa un 80,8\%.

A niveles previos, en la enseñanza media, se observa, asimismo, una especialización, pero ésta no favorecería a los hombres, ya que se trata de estudios que se orientan hacia ocupaciones manuales: la formación profesional de nivel medio, que no llega a alcanzar el 30\% de toda la matrícula de enseñanza media, es mayoritariamente masculina: $56,8 \%$. Cuanto más intelectualizada es la formación, con tanta mayor probabilidad habrá mayoría femenina en ella.

Sin embargo, cabe preguntarse también sobre la dirección causal existente entre valorización social de la profesión y su feminización. Decir que las mujeres se dedican a las ocupaciones menos cotizadas supone aceptar el supuesto de que el rendimiento económico de las profesiones no tiene carácter social, que no está inscripto en las relaciones de género y que es independiente de quienes la desempeñan. Este argumento permanece preso de una valoración social que está ya afectada por la jerarquía de género. Propongo considerar la inversión de la relación causal: las profesiones son menos valoradas porque se han feminizado; la masculinización incrementa el valor social de la credencial.

Por último, hay una importante diferencia entre la feminización de la universidad pública en comparación con las privadas. Numéricamente, la educación universitaria privada ronda el $10 \%$ del total de alumnos universitarios - y no se cuentan acá los estudiantes de formación docenteresante notar que, dentro del universo privado, las mujeres están porcentualmente por debajo de los hombres en el momento del ingreso (47\%), aunque logran superar el 50\% al egreso. Parece ser, entonces, que la educación públi$\mathrm{ca}$ - que es gratuita todos los niveles y de libre acceso en la universidad- es la que más favorece el ingreso y el egreso de las mujeres, posiblemente porque la opción por seguir estudios universitarios sólo depende de ellas mismas - y no de la disponibilidad económica del hogar o del éxito de la negociación con otros dentro del mismo.

\section{La tasa de actividad}

Se ha argumentado que las mujeres se vuelcan a las aulas universitarias porque no participan del mercado de empleo, o lo hacen en menor medida que los hombres. Sin embargo, las estudiantes mujeres parecen tener altas tasas de actividad, similares a las de sus compañeros de aulas. Trabaja o busca trabajo el 79,7\% de las estudiantes mujeres de la UR (Estadísticas básicas de la UR, 2003); cifra muy similar al 82,1\% que registran los estudiantes hombres. La tasa de actividad femenina de las estudiantes universitarias se ubica 18 puntos por encima de la tasa general de actividad, 35 puntos por encima de la tasa de actividad femenina. Las tasas de empleo de estas mujeres $(57,1 \%)$ son sólo levemente inferiores a las tasas generales de empleo que reporta el INE para 
mujeres mayores de 25 años (59\% en 2006), y superan en doce puntos a la tasa general de empleo femenino (45\%).

Esta evidencia no parece sostener el supuesto de la división de tareas según la cual las mujeres estudian porque son inactivas o presentan tasas de actividad sensiblemente inferiores a los hombres. Las mujeres son el $63 \%$ de los estudiantes, el 60\% de los estudiantes que trabajan y el 68\% de los que buscan trabajo. Aproximadamente el $80 \%$ de los estudiantes de la UR, sean hombres o mujeres, son activos y combinan su trabajo con las obligaciones académicas. La gran diferencia sigue estando en el gran peso que tienen las mujeres en la matrícula universitaria.

En conclusión, desde un punto de vista estrictamente cuantitativo, no parece haber evidencias que apoyen a la teoría de la reproducción. Tres de cada cuatro estudiantes de enseñanza terciaria son mujeres, lo que indica que han logrado superar mejor que sus coetáneos varones cualquier posible presión seleccionadora del sistema escolar. Ahora bien, ¿cómo se explica este notable éxito?

Para responder a esta pregunta, recurrimos a las técnicas cualitativas, a fin de interpretar los universos simbólicos y las prácticas que ayudan a las mujeres en su camino hacia el éxito educativo.

\section{Las mujeres: discursos y prácticas}

De los discursos producidos por las estudiantes universitarias en entrevistas en profundidad y en grupos de discusión, parece resultar que ellas perciben con claridad, tanto su situación subordinada en las relaciones de género en el mundo laboral, como el estrechamiento vital y de expectativas que supondría la adopción del rol tradicional de esposa y madre; como consecuencia, se valen del sistema educativo para acceder a aquellos campos profesionales donde parece haber más oportunidades:

[...] yo soy de Tacuarembó, terminé de hacer el liceo, me planteo [...] mujer, yo [...] ¿qué hago? ¿me voy a estudiar? Montevideo, toda una inversión, todo un tema, buscar un lugar, todo, si me quedo, ¿qué hago? Magisterio, está lleno, maestras, bueno, lleno, todo el mundo, ¿no? Mujer... bueno, trabajo, ¿̨en qué trabajo? Tenés zapaterías, tiendas, pero más de eso expectativas no hay, o sea hay pocos lugares, vas al centro, recorrés el centro, trabajo, pero veo más hombres trabajando que mujeres, este..., entonces veo que las expectativas para una mujer son... en el mercado laboral son... [...] Entonces, una mujer, bueno, ¿qué hacés?, es aburrido, qué, me caso, tengo hijos, la única expectativa [risas]..., o soy maestra o me voy y estudio. (Inés, G1)

[...] al [...] no tener las mismas oportunidades laborales que los hombres, requerimos mayor cantidad de años de estudio como para estar más equilibradas. (Gisella, G2)

Esta salida, que muchas veces parece tomar la forma de una estrategia compleja, parece apoyarse en algunos mecanismos complementarios: 
a) El meritocratismo, vale decir, la preferencia por opciones formales y acreditables, que culminan en titulaciones, más que por la apuesta a la formación en servicio o a través de la práctica. La búsqueda de títulos y acreditaciones no es para las mujeres sólo un modo de hablar sobre la educación, sino que parece reflejar, por un mecanismo de sobrecalificación compensatoria, la necesidad de objetivar unos méritos que, de otra manera, los demás no estarían dispuestos a reconocer. En las declaraciones de las estudiantes no faltan referencias concretas a dos de las actitudes más típicamente asociadas a lo masculino: la competencia (sobre todo con hombres) y la ambición (o la negativa a conformarse «con poco»):

Estudiar mucho y superarme y no quedarme con esto, si no, no voy a llegar a nada, porque es así..., porque va a haber otros, hombres, que tengan lo mismo que yo y van a elegirlos a ellos, yo sigo pensando que la sociedad uruguaya es machista y que hay más hombres en la tele y en el gobierno también, para mí es así. (Natalí, G2)

Estoy a punto de recibirme de Ingeniería en computación y pienso en reordenar mi vida y quizás solicitar una beca. Pienso no conformarme con poco y hacer todo el mérito posible para tener el lugar que yo quiero. (Beatriz, G1)

Por otro lado, también puede haber mucho de autodesvalorización personal en algunas manifestaciones de las estudiantes, pero, paradójicamente, es esa conciencia amplificada de una supuesta "medianía» la que alimenta el empeño de algunas mujeres dentro del sistema educativo:

Me voy a tener que romper mucho para conseguir algo, nadie me va a dar nada, y siendo una persona así, mediana, no voy a conseguir nada, voy a conseguir algo pero del montón, si no hago más cursos, si no me la juego, si no hago más estudios, si no hago más no voy a crecer. (Ent. 8f)

La sobrecalificación femenina se expresa, además, en otros dos mecanismos que ya habíamos observado antes en otra investigación (Marrero, 2000): la prolongación de los estudios más allá del grado y el postgrado, y la postergación de los gustos personales a fin de mejorar las oportunidades profesionales. Esto es bien claro en el siguiente fragmento, de una mujer. Obsérvese la diferencia de énfasis que existe en comparación con los dichos del hombre que habla a continuación.

P: ¿Vas a hacer otros estudios después de terminar la carrera?

R: Exacto, postgrado en Relaciones Laborales y después la parte de Internacional Público, porque esto es lo que tiene más mercado, no hay mucha gente. No podés ser abogada de familia porque hay ochenta..., no lo voy a hacer por más que me gusta..., no lo voy a hacer porque no hay... (Ent. If)

Si hoy me decís..., no. Estoy bastante cansado, quiero terminar de una vez [risas], y después lo más seguro en cuanto me empiece a sobrar el tiempo, si 
llego y termino haré un postgrado, pero por ahora lo que me importa es terminar de una vez por todas en la facultad, que se me está yendo bastante larga [risas]. (Ent. $2 \mathrm{~m})$.

b) El sobreesfuerzo pragmático, que supone una completa ordenación racionalizada de la vida a efectos de perseguir consecuentemente los fines propuestos, a veces con gran costo personal. Las estudiantes universitarias suelen relatar cómo organizan su jornada para compatibilizar sus obligaciones laborales con las académicas y las domésticas, algunas veces, con limitaciones económicas severas. Sin embargo, el relato de sus jornadas no adquiere la forma de un lamento sobre su situación, sino que parecen naturalizar el sobreesfuerzo, o aún, lo ven como una condición para lograr un mayor rendimiento.

[...] de mañana me levanto, estudio un poco, hago algunas tareas de la casa, pero siempre y cuando el día anterior haya dejado la comida pronta, así no tengo que cocinar para el mediodía; entro a trabajar a las dos y media de la tarde, está el tema económico también, [...] entonces claro, salgo cuarenta minutos antes para no tomarme ómnibus, llego a casa, [...] a veces también las reuniones con grupos, digo, después del trabajo, y cuando llegaba a casa, [...] tener que preparar la comida para el otro día, trataba de organizarme así... (Ent. 1f)

Esta apretada rutina, que para muchas estudiantes forma parte de su cotidianeidad, es ya un elemento constitutivo de una simbología social que, al impulso de la propaganda de productos de todo tipo, ha forjado una imagen de las mujeres como seres perfectos, capaces de realizar todas las tareas posibles, en condiciones óptimas. Sobre esto, medio en serio y medio en broma, coinciden algunas estudiantes en un grupo de discusión:

MARCELA: La supermujer.

Gisella: ¡Claro!

NATALí: Tiene que seguir manteniendo las casa bien como antes, pero también ser buena profesional.

CARLA: Supradyn ${ }^{3}$, mujeres perfectas que se toman un Supradyn y hacen de todo, y entonces atienden a los hijos, al marido, trabajan, estudian, saltan a la cuerda, no sé, lo que sea, eso de fuiste a trabajar, volviste... dura 78 horas más o menos el día de esas mujeres, y son perfectas termina el día y están... (G2)

[...] agotadas, podría pensarse, pero no es el caso de todas:

[...] me pasó desde siempre, cuanto más ocupada estoy, mejor me va [risas], es impresionante. [...] cuando estoy realmente encasillada y tengo que ordenar-

3. Se refiere a un "preparado polivitamínico con 12 vitaminas, 8 minerales y oligoelementos», producido por Bayer recomendado para el público femenino. 
me, organizarme, y el tiempo lo tengo limitado [es] cuando mejor me va y cuanto más cosas... más ganas de hacer cosas tengo. (Beatriz, G1)

c) Complejización de estrategias donde se superponen consideraciones laborales, académicas y domésticas y afectivas. En las mujeres, las carreras universitarias forman parte de una planificación compleja y de largo plazo, donde se conjugan los proyectos de inserción laboral, la pareja y el matrimonio, los hijos y, por qué no, también la disolución de la pareja y del matrimonio. Veamos:

Pero justamente por eso cuando salimos del liceo y hacemos la carrera y como que uno va planificando más la vida hacia adelante y [...] va prolongando más el hecho de formar una familia, como que uno espera a tener ya la vida más asentada, una carrera hecha, un trabajo más estable para después formar tu familia un proyecto más a largo plazo. (Gisella, G2)

[...] en el inconsciente una sabe que si ya estudió y tiene una carrera universitaria y se puede dentro de todo mantener está más..., digamos, protegida, al momento de tener hijos o de casarse, que después si te pasa que te tenés que divorciar o que después tenés que estar por... vos sola tenés algo... [...] En el momento de la separación en cuanto a la unión libre, no hay tantas leyes como el casamiento, de lo que te tiene que quedar si te tiene que dar algo o no, es más bien todo separado, entonces te separás y ta, cada uno se lleva lo que cada uno hizo y no hay nada que le pueda comprobar legalmente que fue de los dos y ahí también las mujeres encuentran..., en el estudio, un respaldo. (Mariela G2)

d) Cierta acomodación, en las conductas, respecto a las definiciones tradicionales de los roles de género. Si bien es notorio que las mujeres adoptaron un rol activo en la vida pública, que se expresa a través de las altas tasas de actividad, y en la feminización de la educación a todos los niveles, y aunque en sus discursos se muestran muy conscientes de sus propósitos en esos terrenos a largo plazo, parece haber, en su conducta, una disposición a adoptar los comportamientos que tradicionalmente definían la condición femenina: la pasividad, el silencio, la invisibilidad.

Esto fue particularmente notorio en una asamblea estudiantil de unos quinientos asistentes en la que aplicamos una observación participante. Durante unas dos horas de asamblea, hubo 18 oradores; sólo 5 fueron mujeres y, entre todas, usaron solamente 9 minutos y 38 segundos. Los hombres, en cambio, hablaron durante 1 hora y 21 minutos. Un solo hombre habló 25 minutos y 23 segundos - cuando el límite para el uso de la palabra era de 3 minutos-, casi el triple que las cinco mujeres juntas. En promedio, las mujeres hablaron 1 minuto y 55 segundos; los varones, 6 minutos y 14 segundos, más del triple. Una mujer registró el récord de brevedad ante el micrófono: sólo 36 segundos. Todas las mujeres tomaron la palabra para proponer mociones de orden, y no para expresar sus opiniones sobre el asunto sustantivo que se estaba decidiendo. 
Por otro lado, la renuencia de las mujeres a intervenir fue fácil de comprender: dos de ellas fueron abucheadas y ambas se vieron en la necesidad de invocar su expediente académico para hacer valer sus propuestas: una era una excelente estudiante a punto de egresar y la otra se encontraba cursando, en esa facultad, su segunda carrera universitaria.

Pero parece más plausible interpretar el silencio femenino en términos de estrategia, que de conformismo con el tradicional silenciamiento de las mujeres:

$\mathrm{R}:[\ldots]$ me he dado cuenta que me favorece ser callada, no meterme mucho en cosas... [...] es mejor ser un número más, ahí adentro. (Ent.1f)

$\mathrm{P}:$ ¿Y cuáles son tus características como estudiante, digamos, que crees que más te perjudican?

R: Ser sociable..., cuanto más sociable sos, más la gente habla [de] ti [por] detrás, uno tiene que ser como... como un vidrio [...] polarizado, o sea que vos puedas ver y que no te vean tanto. (Ent. 9f)

Explicitando con total naturalidad el tipo de prejuicios al que se exponen las mujeres al tomar la palabra en el espacio público, un estudiante hombre dice, acerca de sus compañeras:

R: La típica estudiante..., eh, una histérica [...] el hablar en clase y el participar pero no por aportar nada sino por el hacerse notar. [...] Claro, una actitud [de] histérico, hablando de [...] la neurosis histérica, ¿ta?, que se caracteriza por el hacerse ver y el buscar llamar la atención, tá, bueno, [...] el hablar y el intervenir no por tener dudas y no entender, o por tener aportes para hacer, sino por el hecho de decir «acá estoy», «véanme». (Ent. $7 \mathrm{~m}$ )

e) La falta de percepción de la discriminación dentro de las aulas. Tanto en los grupos de discusión como en las entrevistas, se abordó directamente la cuestión de la discriminación dentro de las aulas. La respuesta fue muy clara: las mujeres no perciben discriminación dentro de la universidad, en las aulas, en la vida escolar en general. Posiblemente la haya, como hemos tenido ocasión de vislumbrar; pero tal vez en términos relativos, no sea suficiente como para sobrepasar un umbral de sensibilidad que ha sido formado fuera de la institución educativa, en contextos de alta discriminación y subordinación. Con todo, esto no significa que no sean conscientes de las dificultades con las que se enfrentarán en el mundo del trabajo, como ya hemos visto. Para expresarlo con claridad, basta repetir las palabras de una estudiante: «No, me parece que no. [...] creo que hoy en día no la hay, o la hay pero menos, yo no la siento, no la viví, cuando empiece a trabajar sí. (Ent. 8f)

\section{Los hombres...}

Si hay algo que resultó claro de la aplicación de las distintas técnicas cualitativas, fue el amplísimo dominio masculino del espacio público, de la oratoria y 
de la visibilidad. Contrariamente al estereotipo tradicional de la mujer «habladora", y contrariando la superioridad femenina en el uso del lenguaje que ponen de manifiesto reiteradas pruebas de aprovechamiento escolar (por ejemplo, las pruebas Pisa), o la antelación de las niñas en la adquisición del lenguaje durante la primera infancia, resulta que la palabra oral ha terminado siendo un patrimonio claramente masculino. Las cifras ya citadas sobre el uso de la palabra en la asamblea estudiantil parece ser una prueba suficiente, que se agrega a muchas otras aportadas por otras investigaciones (entre otras, Subirats y Brullet, 1988). En este caso, fue claro que las mujeres concurrieron a la asamblea y permanecieron en ella tratando de incidir en los aspectos formales de la misma: presentando mociones que fijaran hora de finalización, que se cerrara la lista de oradores y que se votara. Y luego, por supuesto, aportando su voto a una decisión que, probablemente, habían tomado antes de concurrir.

Pero si volvemos al centro de lo que es nuestra cuestión, fue claro también en los discursos de los hombres, en grupos de discusión y en entrevistas, la invocación de más razones a favor del abandono de los estudios. Un solo estudiante aportó tres argumentos distintos: el sentimiento de «estar perdiendo el tiempo", la humillación de tener que soportar malos docentes y la masificación en las aulas. Pero, más allá de sus argumentos, que objetivamente deberían afectar por igual a hombres y mujeres, reviste especial interés el diálogo que se produce cuando una mujer lo interpela y discute su postura:

RODRIGO: [...] las veces que se me cruzó por la cabeza dejar la... la carrera, y creo que, eh, las carreras universitarias son... algunas son largas, este [...] a veces te hacen sentir que estás perdiendo el tiempo, [...] igual yo sigo peleándola, pero por momentos he visto gente que ha abandonado, por decir «noooo, ya está loco!, ya está!, tengo 23 años y estoy acá, frente al nabo [imbécil, en uruguayo] este que... está a mi nivel» [risas], entonces, claro, entonces hay como una especie de decir, «nooo, ¿qué hago acá?, me voy a laburar y a hacer algo más productivo", sentirte más productivo en la vida, ¿̨no? (Rodrigo G155)

BEATRIZ (interrumpe): Yo estoy de acuerdo contigo, pero digo, no creo que sea válido, vos no podés... ¿porque el que está adelante es un nabo voy a dejar mi carrera? ¿y es válido? para mí eso no es válido.

[...]

RODRIGO: la universidad nos puede llegar a desmotivar, [...] En mi facultad pasa que vos vas en primero, $y$ hay un salón donde entran 300 personas, pero van 500, y hay 80 que se quedan en la puerta escuchando, y hay 140 que se..., 120 , perdón, 120 que se van, porque llegaron diez minutos tarde y no hay lugar, ¿tá?. Y esas cosas digo... ta, yo llegaba temprano a primero, ta, y me sentaba adelante, pero si llegaste tarde, y... ta, y marchás, y si te pasa eso en todas las materias...

Otro argumento reiterado es que, al parecer, los hombres soportan de peor manera el esfuerzo físico que supone combinar más de una tarea durante la jornada. Basta acá transcribir las palabras de un estudiante: 
[...] entré a laburar, y ahora a principios del 2006 arranqué la facultad, me anoté en las clases de 4to. [...] y no soporté, y trabajaba seis horas y media, tenía cuatro horas de clase y... no me daba, ta! Y yo tenía compañeras de laburo, compañeras de trabajo que estudiaban Medicina, Abogacía, que eran compañeras mías, trabajaban lo mismo que yo, trabajaban y estudiaban, y yo no pude, no pude, no digo que sea imposible, yo no podía, yo llegaba a casa muerto y hacía cualquier cosa menos estudiar, tá, y dejé de laburar, digo, también tá, tengo esa suerte, pude, pude dejar de trabajar y decidir seguir estudiando, pero tenía compañeras que lo hacían, yo no pude. (Juan G1)

\section{Una interpretación: el doble nivel del orden escolar}

Ahora bien: las mujeres tienen más éxito en la institución escolar. Llegan en mayores cantidades, progresan mejor, egresan más. Tienen sus objetivos claros y diseñan estrategias que persiguen con un esfuerzo naturalizado, aunque su comportamiento en instancias públicas muestra una renuencia a disputar, con los hombres, tanto espacio, como tiempo y visibilidad. ¿Cómo interpretar estas aparentes contradicciones? ¿Cómo se produce su éxito y a qué causas puede ser imputado?

Propongo que en este gran aparato de producción y legitimación de ordenamientos sociales que es el sistema escolar, distingamos dos niveles diferentes, pero conectados:

a) Por un lado, el del conjunto de normas explícitas que sirven de fundamento a la escuela como institución educativa como un ámbito diferente del mundo social y cultural de lo adscriptivo, lo heredado y lo desigual: el valor del conocimiento escolar adquirido, el universalismo, el mérito y la igualdad básica de todos los estudiantes. En lo explícito, la escuela se constituye como un campo donde vienen a morir las leyes usuales de la interacción social, signadas por asimetrías de todo tipo; sólo perviven aquí las jerarquías derivadas del saber escolar, en especial, la del docente respecto del alumno. Para los actores de la institución - docentes, alumnos, padres - es este nivel (de lo explícitamente prescripto) el que prevalece como fuente de evaluación y legitimación de las acciones; tiene una existencia real para los participantes y constituye un elemento central según el cual orientan su conducta, la evalúan y actúan en consecuencia. Estas normas, que para algunos no constituyen más que la forma «ideológica» que asume la escuela en su función «reproductora», son, en los hechos, una de las fuerzas más poderosas que, dentro de la escuela, impulsan y permiten a los sujetos con identidad subordinada, a sobreponerse a aquellas fuerzas invisibles que actúan en su contra y cuya naturaleza, al menos en parte, ignoran. Para las mujeres, este es el mundo del reconocimiento y de la visibilización.

b) Por otro lado, se encuentra el conjunto de reglas implícitas que constituye el campo social escolar como un campo de fuerzas asimétrico regido por 
supuestos indiscutibles que premian el valor derivado de cualidades adscriptivas carismáticamente connotadas, en continuidad con el espacio extraescolar de donde proviene. Desde este nivel permea hacia el de la norma escolar, el peso de la dignidad de «los herederos», como los llama Bourdieu, pero también, de lo masculino, de lo europeo, de lo caucásico, de lo occidental, de lo norteño. Los conocimientos y los reconocimientos que se transan en el espacio de interacción socioescolar tienen que ver con el «ser», a diferencia de lo que se negocia en el nivel explícito, que es el del «hacer». Aún las recompensas escolares - como calificaciones, promociones, premios- pueden servir acá para ratificar el valor de quien «es» a través de lo que «hace», pero lo primero es lo definitorio. Para las mujeres, este es el mundo del menoscabo y de la invisibilización.

Ambos niveles son necesarios para describir y explicar lo que pasa en la escuela. Ninguna investigación que se enfoque exclusivamente en uno de los niveles, podrá explicar lo que ocurre en la escuela, y ninguna postura político-práctica será adecuada si no los tiene presentes a ambos, con el riesgo de caer, bien en la ingenuidad, bien en el cinismo. Si bien la sociología de la educación hizo una contribución notable al poner de manifiesto «la cara oculta de la escuela», con frecuencia contribuyó a desviar la atención del papel de la escuela en la constitución de un «sentido común» universalista y meritocrático que distorsiona y puede llevar a sustituir en parte al sentido común del mundo social extraescolar.

En esta perspectiva, el éxito en el tránsito por la institución escolar puede pensarse como una función de la capacidad para obtener reconocimiento por la inserción adecuada en el mundo de la prescripción escolar, en el del ser social, o en ambos. Como se puede apreciar de modo inmediato, uno de los mundos —el del ser social— queda excluido para todos aquellos con una «identidad subordinada», si no en su acceso, ya que todos forman parte del espacio social de la escuela y de su jerarquía, aunque más no sea como parte del orden subordinado, sí en sus posibilidades de obtener reconocimiento a partir de él. Para los pobres, o para las minorías étnicas, pero también para las niñas en las escuelas mixtas, que suelen encontrarse subordinadas en el mundo de las reglas implícitas que consagran una jerarquía sexual que beneficia a los varones, el ámbito del desempeño escolar es el único que ofrece recompensas claras, mensurables y predecibles, a esfuerzos también claros, mensurables y predecibles. Como consecuencia paradójica, la valoración que reciben las mujeres dependerá, entonces, de lo que se «hace»—se aprende, se sabe, se escribe, se recita, se exhibe-, y no de lo que se «es», se piensa, se imagina, se considera o se opina. La retracción de las niñas y de las mujeres de los ámbitos "públicos», donde se desempeñan tan bien los varones, puede ser vista como un resultado de una experiencia social y también escolar (implícita) que premia en algunas - y algunos - sólo aquello que depende del logro objetivo ligado a la dedicación y al esfuerzo desde una identidad cuyo valor frecuentemente nadie — ni siquiera la propia persona- aprecia realmente. 
Por eso, el sistema escolar ofrece a las mujeres por primera vez $-\mathrm{y}$ a veces por última vez - la posibilidad de obtener información independiente sobre su valor personal, a partir de sus propios talentos, esfuerzos y realizaciones. Por primera vez, el ser mujer u hombre, y el comportarse como tales, no es lo importante; por primera vez, el comportamiento prescripto es idéntico para todos. El papel de estudiante dice exigir los mismos esfuerzos, los mismos desempeños y las mismas recompensas, sin importar ninguna otra cosa. Pero el probarse exclusivamente en ese campo tiene costos altos, ligados con el evidente y sostenido esfuerzo que conlleva. Si todo lo que puede reclamarse a ese nivel tiene que ver con lo que se "logra», todo el reconocimiento dependerá de la cantidad de tiempo y esfuerzo que se está dispuesta a poner en el empeño. Basta recordar acá las palabras - y las jornadas - de las estudiantes uruguayas.

Por otra parte, el rechazo que frecuentemente sufren las alumnas aplicadas en las aulas por parte de sus pares — que bien puede ser ejemplificado a través de la ligera e indiscriminada imputación de "neurosis histérica» que hacía un estudiante que ya citamos - no puede repararse con mayor empeño. Porque sin importar lo brillante que resulte el desempeño de las mujeres, se trata de un comportamiento que, a la vez que delata una identidad devaluada, hace algo más: revela el desconocimiento de las reglas implícitas, al reclamar de un modo - que en este contexto es siempre-impertinente el reconocimiento del orden explícito, como el único válido del mundo escolar. Esto contribuye, así, a poner de manifiesto el carácter adquirido del saber escolar, contrariando lo que Bourdieu llama «la ideología del talento natural» y cuestionando lo que la cultura escolar exalta: el genio, el carisma, lo único. Con su respeto a la norma escolar, estas mujeres terminan, paradójicamente, transgrediendo las bases mismas del orden social implícito, al obligar a los otros a reconocerlas como sujetos por derecho propio, cuando lo que hacen es aprovechar el acceso a un rol igualitario en tanto alumnas, para reclamar el cumplimiento de un orden universalista dentro del cual se visualizan como sujetos de su propia suerte educativa, social y personal. En esto, coincido con Subirats y Brullet en enfatizar las ventajas que tiene para las mujeres el cumplimiento de las normas formales universalistas (Subirats y Brullet, 1988: 133), aunque, a la luz de nuestros resultados, parece improbable sostener - como dicen las autoras- que las mujeres perciban en la escuela la desvalorización que se asocia a su condición femenina. Lejos de haber desarrollado una conciencia de su papel femenino en el orden escolar, las mujeres parecen moverse casi exclusivamente en el orden de lo explícito, como si las reglas implícitas no existieran.

Si esto puede iluminar en parte el éxito de las mujeres, hace falta algo más para interpretar la temprana deserción de los hombres. Es que los procesos implícitos son vividos de modos distintos entre las alumnas y los alumnos de distintas clases sociales. Mientras que para las alumnas de clases privilegiadas, la vigencia de su subordinación dentro de un orden sociosexual es tan real como para las alumnas de clases subordinadas, los varones de clases bajas pueden sufrir, en la escuela, un tipo de desvalorización nunca experimentado antes: 
el que los sitúa en un lugar de segundo orden en relación con lo femenino. Si en lo implícito, los varones de clases bajas disfrutan de las ventajas debido al género, en lo explícito deben disputar el reconocimiento con los «herederos» en relación con los cuales siempre están mal parados, pero también con las alumnas que juegan según las normas de la escuela. Para estos alumnos varones, aceptar las normas escolares supone situarse en el mundo femenino por tres vías simultáneas: por alejamiento de lo masculino privilegiado que cultiva el distanciamiento diletante como forma de manifestar su superioridad, por asimilación a la cultura del colectivo femenino de alumnas aplicadas y por aceptación de la autoridad de un docente que, casi sin excepción — sobre todo en los niveles secundarios, cuando la mayor parte de la deserción tiene lugar-, es una mujer.

Si el esfuerzo se convierte en un modo "femenino" de ser en la escuela, esto puede afectar también a la construcción de un modo de ser escolar masculino entre los herederos, lo cual acentua en ellos algunos rasgos característicos del "gesto vacío" al que se refería Bourdieu. Por ejemplo, el recurso a la exhibición de su capital cultural mediante intervenciones orales breves, episódicas y a veces atinadas, pueden lograr el fin que se proponen, que es el de obtener recompensas escolares por la vía del reconocimiento inmediato de unos saberes supuestos, que no necesitan ser verificados. Si bien estas estrategias requieren de un cierto ingenio, no contribuyen a generar el tipo de hábitos que serán necesarios cuando el capital cultural no baste: en asignaturas muy técnicas, en niveles superiores o en áreas desconocidas. Aunque esto pueda llegar a comprometer la suerte escolar de estos varones - tal como muestran las estadísticas - contribuye, mientras tanto, a alimentar la «ideología del don» o del «talento» natural (Bourdieu, 2003: 106-113), lo cual confirma los estereotipos discriminadores que atribuyen a los varones una mayor inteligencia, algunos de los cuales fueron compartidos por las estudiantes que entrevistamos.

Además, el sexo del docente no es un simple dato. El cosmos escolar - sobre todo a niveles preuniversitarios- es un mundo regido por mujeres (maestras, profesoras, directoras, secretarias, etc.). Aceptar este orden supone, entonces, aceptar a las mujeres como fuente de conocimiento sobre el mundo y sobre cuales son los modos de adquirir ese conocimiento, de mostrarlo y de evaluarlo; supone aceptar que sean las mujeres las que dicten las normas y las hagan cumplir. Es esta aceptación lo que se vuelve difícil si se proviene de una cultura de clase subordinada, basada en la exaltación de una masculinidad que se constituye por oposición a lo femenino, y que, por asimilación de lo femenino a lo escolar, se termina constituyendo por su oposición a lo escolar (Willis, 1988). En la medida en que la deserción masculina y la consecuente feminización matricular siguen ligados a la implícita superioridad masculina, se vuelve evidente la tensión entre "la superioridad natural» de los hombres y «la superioridad escolar» de las mujeres. Mientras que, en cuanto a la clase social, el orden escolar confirmaba la jerarquía implícita, en cuestiones de género, viene a contradecirla, lo que da como resultado — paradójicamente- una desvalorización relativa de las titulaciones por parte de los varones, pero también, 
curiosamente, por parte de las propias mujeres. A veces presas del supuesto de la superioridad masculina, e inseguras de su propio valor, las mujeres terminan sospechando del valor de las credenciales que obtienen. Desde una conciencia amplificada de los defectos de su formación, y del desarrollo de la autocrítica por una prolongada práctica de la ética del esfuerzo escolar, se convencen de que esas credenciales no valen lo que parecen. Muchos varones permanecen, así, simbólicamente, por encima de la rutina escolar, de sus normas y de sus reconocimientos.

Pero esto no puede conducirnos a concluir - con Bourdieu - que todo cambia para que todo siga como está. Atendiendo a sus resultados, el sistema educativo premia, decididamente, la estrategia femenina, y la premia justamente en aquellos aspectos y por aquellos mecanismos que son propios de la institución escolar: el mérito, el desempeño, la igualdad y el universalismo. Por eso no parece válida la hipótesis de la «vulneración de la autoconfianza» de las mujeres como un fenómeno escolar.

Primero, porque ella parece sugerir que las mujeres ingresan en las aulas con su confianza intacta, con una identidad construida sin el más leve roce de los múltiples mensajes desvalorizadores de lo femenino que abundan en sociedades construidas en clave masculina. Es el mundo implícito de las jerarquías sociosexuales, lo que vulnera la confianza tanto de las niñas como de otros alumnos con identidades subordinadas. Segundo, porque es en lo escolar donde se muestra el éxito de las mujeres. Son las pretensiones en las que se legitima la escuela lo que permite a las mujeres, desde su ingreso a ella, afirmar su propia voluntad de ser reconocidas y valoradas, aún a costa de ser valoradas por aquello a lo que no se le da, realmente, valor en unas culturas que aprecian sólo el don de la distinción masculina. Los resultados curriculares de millones de mujeres alrededor del mundo muestran que esos son, justamente, los métodos y los conocimientos que hay que adquirir, no sólo para obtener unas credenciales difíciles de sobreestimar, sino también para asumir, dentro de los límites y las condiciones de nuestro tiempo, la responsabilidad de un destino propio. Lejos de representar la identificación con un modelo masculino de ver el mundo y estar en él — como también se ha llegado a sostener-, estos logros son la condición para que cada una de las mujeres se encuentre a la par de sus coetáneos varones, en la posesión de los recursos cognitivos y actitudinales necesarios para desafiar con éxito el estrechamiento de los horizontes vitales impuesto por un orden sociocultural que naturaliza su inferiorización.

En suma, la correcta identificación de los lugares donde todavía se procesa la discriminación parece ser una condición necesaria para la remoción de los obstáculos hacia el logro de la igualdad en sociedades modernas y democráticas. Y a juzgar por los resultados que consiguen las mujeres en ella, y por los modos como distribuye sus recompensas, la escuela parece, por lo que hemos visto, a salvo de la acusación de ser responsable de la perpetuación de las asimetrías de género. 


\section{Bibliografía}

AGUIRRE, R. (1998). Sociología y género: Las relaciones entre hombres y mujeres bajo sospecha. Montevideo: Universidad de la República. CSIC-Doble clic soluciones editoriales.

BECK, U. (1998). La sociedad del riesgo. Barcelona: Paidós.

BECK, U.; BECK-GERNSHEIM, E. (2001). El normal caos del amor: Las nuevas formas de la relación amorosa. Barcelona: Paidós.

BONDER, G. (1993). La igualdad de oportunidades para mujeres y varones: una meta educativa. Buenos Aires: Ministerio de Cultura y Educación.

Bourdieu, P. (2000). La dominación masculina. Barcelona: Anagrama.

- (2003). Los herederos. Los estudiantes y la cultura. Buenos Aires: Siglo XXI.

Coscojuela, R.; Subias, R. (1993). "¿Hombres dirigentes y mujeres ejecutoras?». Cuadernos de Pedagogía, 211, febrero.

De Miguel, A. «Feminismos». En: Amorós, C. (coord.). 10 palabras clave sobre movimientos sociales. Pamplona: Verbo Divino.

FEMENías, M. L. (2002). Perfiles del feminismo iberoamericano. Buenos Aires: Catálogos. GARCÍA de LEÓn, M. A. (1994). Élites discriminadas: Sobre el poder de las mujeres. Barcelona: Anthropos.

LipOVETSKY, G. (1999). La tercera mujer. Barcelona: Anagrama.

LOMAS, C. (comp.) (1999). ¿Iguales o diferentes? Género, diferencia sexual, lenguaje y educación. Barcelona: Paidós Educador.

Marrero, A. (2000). Mirando al presente, planeando el futuro. Estrategias de género entre estudiantes de bachillerato uruguayos. Buenos Aires: UBA-IIEG.

Morgade, G. (2001). Aprender a ser mujer. Aprender a ser varón. Buenos Aires: Novedades Educativas.

Mosconi, N. (1998). Diferencia de sexos y relación con el saber. Buenos Aires: UBA.

OAKLEY, A. (1972). Sex, gender \& society. Londres: Maurice Temple Smith.

- (1981). Subject women. Oxford: Martin Robertson.

- (1985). Sex, gender \& society. Revised Edition Hampshire: Arena, Gower Publishing.

O'BRIEN, M. (1983). "Feminism and education: A critical review essay». Resources for Feminst Research, 12 (3): 3-16.

Puleo, A. (1993). «Feminismos». En: MARdones, J. M. (dir.). 10 palabras clave sobre movimientos sociales. Pamplona: Verbo Divino.

Spender, D. (ed.) (1981). Men's Studies Modified: The impact of Feminism on the Academic Disciplines. Oxford: Pergamon Press.

Subirats, M. (1999). "Género y escuela». En: LOMAS, C. (comp.). ¿Iguales o diferentes? Género, diferencia sexual, lenguaje y educación. Barcelona: Paidós Educador.

Subirats, M.; BRUllet, C. (1988). Rosa y azul: La transmisión de los géneros en la escuela mixta. Madrid: Instituto de la Mujer.

UNIVERSIDAD DE LA RePÚBLICA (2005). Estadísticas básicas de la Universidad de la República. Dirección General de Planeamiento. 